\author{
International Journal of Management and Sustainability \\ 2014 Vol.3, No.4, pp.234-249 \\ $\operatorname{ISSN}(e): \quad 2306-0662$ \\ $\operatorname{ISSN}(p): 2306-9856$ \\ DOI: 10.18488/journal.11/2014.3.4/11.4.234.249 \\ (C) 2014 Conscientia Beam. All Rights Reserved. \\ (1) cosshark
}

\title{
STOCK MARKET VOLATILITY UNDER SANCTIONS
}

\section{Hojatallah Goudarzi 1}

${ }^{\prime}$ Finance and Insurance Department, Faculty of Management, University of Tehran, Iran

\begin{abstract}
Since 1979, Iran has faced with unilateral and multilateral harsh sanctions due to its nuclear energy program. These sanctions have resulted in significant problem to both sanctioned and sanctioning parties. Given the fact that sanctions have had significant impacts on Iran's economy and since Iran stock market is the barometer of its economy, it is assumed that sanctions affect the Iranian stock market as well. To test this hypothesis, this study studied the Iranian stock market volatility during harsh sanctions using ARCH models. The study found that, despite all sanctions, not only Iran's stock market shows major stylized facts of any stock market's volatility i.e. volatility clustering, fat tails and mean reversion but also it shows no irregularity which could be attributed to effect of sanctions. This finding was consistent with Iranian stock market regulators claiming Iranian stock market growth and the U.S. Congressional Research Service report 2013. Therefore, based on findings, this study concluded that Iranian stock market has not affected by sanctions.
\end{abstract}

Keywords: Stock market, Volatility, Stylize facts, Sanctions and ARCH models.

JEL Classification: G1,G2,G3.

Received: 8 January 2014/ Revised: 23 January 2014/ Accepted: 20 February 2014/ Published: 14 March 2014

\section{INTRODUCTION}

Use of sanctions reaches back to those imposed by Ancient Athens in $436 \mathrm{BC}$ against its neighbor Megara. Since the 19th century, sanctions have been used as a foreign policy tool to forestall war, alleviate public pressure on policy makers, and attempt to change the domestic and foreign policy of adversaries (Hufbauer, 2007).

Over the course of the 20th century, the United States increasingly used sanctions to place pressure on certain nations. The main goal of such a sanction by U.S. is regime change, a change in decision-making, or the release of political prisoners, among others. But the use of sanctions often carries with it other effects on a target nation, including impacts on foreign investment, inflation, and trade (Matthew, 2013).

Sanctions against Iran started by the US over 30 years ago, dates back to the post-1979 Iranian Islamic Revolution initially targeting the oil industry (Pesaran, 2013).These sanctions stem from two main sources, sanctions from the UN Security Council in one hand and sanctions by united State and their allies on the other hand. Following the report by the International 
Atomic Energy Agency Board of Governors regarding Iran's non-compliance with its safeguards agreement, the UN Security Council passed a number of resolutions imposing sanctions on Iran. (Government of Australia, 2013). Along with above mentioned resolution there are other important sanctions, known as Non-UN sanctions mainly imposed by United State and their associates including European Union, China, India, Canada, South Korea and Japan. (Torbat, 2012).

Sanctions have mixed impact on Iran's economy. Oil exports fund nearly half of Iran's government expenditures, and Iran's oil exports have declined to about 1.1 million barrels-less than half of the 2.5 million barrels per day Iran exported during 2011. The loss of revenues from oil, coupled with the cut-off of Iran from the international banking system, has caused a sharp drop in the value of Iran's currency, the Rail; raised inflation to over 50\%, reduced Iran's reserves of foreign exchange; and caused much of Iran's oil revenues to go unused in third-country accounts. (Katzman, 2013).

Despite all of the above mentioned consequences of imposed sanctions, Iranian stock market indicators tell another story and show positive growth during sanctions. TSE's market capitalization as a proxy of Iran's capital market, reach $\$ 164.7$ billion by November 2013, which show 16.5 percent increase compared with $\$ 140.8$ million on Dec 2012. According to the TSE market summary Nov 2013, the Exchange turnover raised to 18,368 million transactions which show a significant increase from 11,883 million at Dec 2012. TSE total turnover value in Nov 2013 reach $\$ 3,293$ million compared with $\$ 1888$ million at the Jan 2013. As another indicator the ratio of market cap to GDP increases to 50 percent (Tehran Stock Exchange, 2013).

While the volatility and its relationship with stock price in financial markets has been well studied from different point of views, due to the rareness of this situation i.e. the imposing harsh international sanctions, little concentration has been paid towards its study on the literature. Therefore, in line with stock markets studies, the main purpose of this study is to investigate volatility and its related stylized facts in the Iranian stock markets using ARCH models.

The rest of this paper is organized as follows. Section 2 deals with the volatility models considered for this paper. The review of literature is presented in section 3. The description of the TEPIX data and the methodology is presented in section 4 . The findings are presented in section 5 and finally section 6 concludes the paper.

\section{MODELS OF VOLATILITY}

ARCH models are capable of modeling and capturing many of the stylized facts of the volatility behavior usually observed in financial time series including time varying volatility or volatility clustering (Zivot and Wang, 2006).The serial correlation in squared returns, or conditional heteroskadasticity (volatility clustering), can be modeled using a simple autoregressive (AR) process for squared residuals. For example, let $y_{t}$ denote a stationary time 
series such as financial returns, then $\mathrm{y}_{\mathrm{t}}$ can be expressed as its mean plus a white noise if there is no significant autocorrelation in $\mathrm{y}_{\mathrm{t}}$ itself:

$$
y_{t}=c+\varepsilon_{t}
$$

where $\mathrm{c}$ is the mean of $\mathrm{y}_{\mathrm{t}}$, and $\varepsilon_{\mathrm{t}}$ is iid with mean zero. To allow for volatility clustering or conditional heteroskadasticity, assume that $\operatorname{Var}_{t-1}\left(\varepsilon_{t}^{2}\right)=\sigma_{t}^{2}$ with $\operatorname{Var}_{t-1}(0)$ denoting the variance conditional on information at time t-1, and

$$
\sigma_{t}^{2}=\alpha_{0}+\alpha_{1} \varepsilon_{t-1}^{2}+\cdots+\alpha_{p} \varepsilon_{t-p}^{2}
$$

Since $\varepsilon_{t}$ has a zero mean, $\operatorname{Var}_{t-1}\left(\varepsilon_{t}^{2}\right)=\sigma_{t}^{2}$, the above equation can be rewritten as:

$$
\varepsilon_{t}^{2}=\alpha_{0}+\alpha_{1} \varepsilon_{t-1}^{2}+\cdots \cdots+\alpha_{p} \varepsilon_{t-p}^{2}+u_{t}
$$

Where $u_{t}=\varepsilon_{t}^{2}-E_{t-1}\left(\varepsilon_{t}^{2}\right)$ is a zero mean white noise process. The above equation represents an $\operatorname{AR}(\mathrm{p})$ process for $\varepsilon_{t}^{2}$, and the model in (1) and (2) is known as the autoregressive conditional heteroscedasticity (ARCH) model of (Engle, 1982), which is usually referred to as the $\mathrm{ARCH}(\mathrm{p})$ model. Before estimating a full ARCH model for a financial time series, it is necessary to test for the presence of $\mathrm{ARCH}$ effects in the residuals. If there are no $\mathrm{ARCH}$ effects in the residuals, then the ARCH model is unnecessary and misspecified.

Since an ARCH model can be written as an AR model in terms of squared residuals as in equation 3,A simple Lagrange Multiplier (LM) test for ARCH effects can be constructed based on the auxiliary regression as in equation 3. Under the null hypothesis that there is no ARCH effects:

$$
H_{\mathrm{o}}=\alpha_{1}=\alpha_{2}=\cdots \cdot \alpha_{P}=\mathrm{O}
$$

The test statistic is

$$
L M=T \cdot R^{2} \sim \chi^{2}(P)
$$

Where $\mathrm{T}$ is the sample size and $R^{2}$ is computed from the regression (3) using estimated residuals. If $\mathrm{P}$-value is smaller than the conventional 5\% level, the null hypothesis that there are no ARCH effects will rejected. In other word, the series under investigation shows volatility clustering or persistence. If the LM test for ARCH effects is significant for a time series, one could proceed to estimate an ARCH model and obtain estimates of the time varying volatility $\sigma^{2}$ based on past history. However, in practice it is often found that a large number of lags $\mathrm{P}$, and thus a large number of parameters are required to obtain a good model fit. A more parsimonious model proposed by (Bollerslev, 1986) replaces the AR model in (equation 2) with the following formulation:

$$
\sigma_{t}^{2}=\alpha_{0}+\sum_{i=1}^{p} \alpha_{i} \varepsilon_{t-i}^{2}+\sum_{j=1}^{q} b_{j} \sigma_{t-j}^{2}
$$


Where the coefficients $\alpha_{i}=(i=0 \ldots, P), b_{j}(j=1 \ldots, q)$, are all assumed to be positive to ensure that the conditional variance $\sigma^{2}$ is always positive. The model in (equation 4) together with (equation 1) is known as the generalized ARCH or GARCH (p, q) model. When $q=0$, the GARCH model reduces to the ARCH model.

Under the GARCH $(p, q)$ model, the conditional variance of $\varepsilon_{t}, \sigma_{t}^{2}$ depends on the squared residuals in the previous p periods, and the conditional variance in the previous $q$ periods. Usually a GARCH $(1,1)$ model with only three parameters in the conditional variance equation is adequate to obtain a good model fit for financial time series (Zivot and Wang, 2006).

\subsection{ARCH Models Specification for TEPIX}

Before estimating ARCH models for a financial time series, taking two steps is necessory.First check for unit roots in the residuals and second test for ARCH effects.

The input series for ARMA needs to be stationary before we can apply Box-Jenkins methodology .The series first needs to be differenced until is stationary. This needs log transforming the data to stabilize the variance. Since the raw data are likely to be non-stationary, an application of $\mathrm{ARCH}$ test is not valid. For this reason, it is usual practice to work with the logs of the changes of the series rather than the series itself.

The presence of unit root in a time series is tested using Augmented Dickey- Fuller test. It tests for a unit root in the univariate representation of time series. For a return series $R_{t}$, the ADF test consists of a regression of the first difference of the series against the series lagged $k$ times as follows:

$$
\Delta r_{t}=\alpha+\delta r_{t-1}+\sum_{i=1}^{p} \beta_{i} \Delta r_{t-i}+\varepsilon_{t}
$$

Or

$$
\Delta r_{t}=r_{t}-r_{t-1} ; r_{t}=\ln \left(R_{t}\right)
$$

The null hypothesis here is the series contains unit root. The acceptance of null hypothesis implies non-stationary. If the ADF test rejects the null hypothesis of a unit root in the return series, that is if the absolute value of ADF statistics exceeds the McKinnon critical value the series is stationary and we can continue to analyze the series.

Before estimating a full $\mathrm{ARCH}$ model for a financial time series, it is necessary to check for the presence of $\mathrm{ARCH}$ effects in the residuals. If there are no $\mathrm{ARCH}$ effects in the residuals, then the ARCH model is unnecessary and misspecified (Zivot and Wang, 2006).

\subsubsection{ARCH Effect Test Process}

Consider the k-variable linear regression model.

$$
y_{t}=\beta_{1}+\beta_{2} x_{2 t}+\cdots+\beta_{k} x_{k t}+u_{t}
$$


In addition, assume that conditional on the information available at time (t-1), the disturbance term distributed as

$$
u_{t} \sim\left[\mathrm{O},\left(\alpha_{\mathrm{O}}+\alpha_{1} u_{t-1}^{2}\right)\right]
$$

That is, $u_{t}$ is normally distributed with zero mean and

$$
\operatorname{Var}\left(u_{t}\right)=\left(\alpha_{0}+\alpha_{1} u_{t-1}^{2}\right)
$$

That is the variance of $u_{t}$ follows an $\mathrm{ARCH}$ (1) process. The variance of $\mathrm{u}$ at time $\mathrm{t}$ is dependent on the squared disturbance at time (t-1), thus giving the appearance of serial correlation. The error variance may depend not only on one lagged term of the squared error term but also on several lagged squared terms as follows:

$$
\operatorname{Var}\left(u_{t}\right)=\sigma_{t}^{2}=\alpha_{0}+\alpha_{1} u_{t-1}^{2}+\alpha_{2} u_{t-1}^{2}+\cdots+\alpha_{p} u_{t-p}^{2}
$$

If there is no autocorrelation in the error variance, we have

$$
H_{0}: \alpha_{1}=\alpha_{2}=\cdots \cdot \cdot=\alpha_{p}=\mathrm{O}
$$

In such a case, $\operatorname{Var}\left(u_{t}\right)=\alpha_{0}$, and we do not have the ARCH effect. Since we do not directly observe $\sigma_{t}^{2}$ Engle has shown that running the following regression can easily test the preceding null hypothesis:

$$
\hat{u}_{t}^{2}=\hat{\alpha}_{0}+\hat{\alpha}_{1} \hat{u}_{t-1}^{2}+\hat{\alpha}_{2} \hat{u}_{t-1}^{2}+\cdots \cdot+\hat{\alpha}_{p} \hat{u}_{t-p}^{2}
$$

Where $u_{t}$, as usual, denote the OLS variance obtained from the original regression model. The null hypothesis can be tested by the usual F test but the ARCH-LM test of Engle 1982 is a common test in this regard. Under ARCH-LM test null hypothesis is homoskedasticity or equality in the variance. Acceptance of this hypothesis imply that, there is no ARCH effects in the under process series. In other word, the data do not show volatility clustering i.e. there is no heteroskadasticity or time varying variance in the data.

Since an ARCH model can be written as an AR model in terms of squared residuals as in

$$
\varepsilon_{t}^{2}=\alpha_{0}+\alpha_{1} \varepsilon_{t-1}^{2}+\cdots+\alpha_{p} \varepsilon_{t-p}^{2}+u_{t}
$$

a simple Lagrange Multiplier (LM) test for ARCH effects can be constructed based on the auxiliary regression.

$$
\varepsilon_{t}^{2}=\alpha_{0}+\alpha_{1} \varepsilon_{t-1}^{2}+\cdots+\alpha_{p} \varepsilon_{t-p}^{2}+u_{t}
$$

Under the null hypothesis that there is no ARCH effects, the test statistic is as follows:

$$
L M=T \cdot R^{2} \sim \chi_{(P)}^{2}
$$


Where $\mathrm{T}$ is the sample size $R^{2}$ is computed from the regression

$$
\varepsilon_{t}^{2}=\alpha_{0}+\alpha_{1} \varepsilon_{t-1}^{2}+\cdots+\alpha_{p} \varepsilon_{t-p}^{2}+u_{t}
$$

using estimated residuals. That is in large sample $T R^{2}$ follows the Chi-square distribution with $\mathrm{df}$ equal to the number of autoregressive terms in the auxiliary regression.

The test statistic is defined as TR2 (the number of observations multiplied by the coefficient of multiple correlation) from the last regression, and it is distributed as a $\chi_{(q)}^{2}$ (Gujarati, 2007). Thus, the test is one of a joint null hypothesis that all q lags of the squared residuals have coefficient values that are not significantly different from zero. If the value of the test statistic is greater than the critical value from the $\chi^{2}$ distribution, then one can reject the null hypothesis. The test can also be thought of as a test for autocorrelation in the squared residuals. Alternatively, if $\mathrm{P}$-value is smaller than the conventional $\alpha \%$ level, the null hypothesis that there are no ARCH effects will rejected. In other word, the series under investigation shows volatility clustering or volatility persistence (Brooks, 2002).

If an ARCH effect is found to be significant, then the specification of an appropriate ARCH model is necessary. In order to identify the ARCH characteristics in TEPIX, the conditional return should be modeled first; the general form of the return can be expressed as a process of autoregressive AR (p), up to (p) lags, as follows:

$$
\boldsymbol{R}_{t}=\alpha_{\mathrm{O}}+\sum_{i=1}^{p} \alpha_{1} \boldsymbol{R}_{t-1}+\varepsilon_{t}
$$

This general form implies that the current return depends not only on $\left(R_{t-1}\right)$ but also on the previous (p) return value $\left(R_{t-p}\right)$. The next step is to construct a series of squared residuals $\left(\varepsilon_{t}^{2}\right)$ based on conditional return to drive the conditional variance. Unlike the OLS assumption of a constant variance of $\left(\varepsilon_{t}, s\right)$, ARCH models assumes that $\left(\varepsilon_{t}, s\right)$ have a non constant variance or heteroscedasticity, denoted by $\left(h_{t}^{2}\right)$. After constructing time series residuals, we modeled the conditional variance in a way that incorporates the $\mathrm{ARCH}$ process of $\left(\varepsilon^{2}\right)$ in the conditional variance with (q) lags.

The general forms of the conditional variance, including (q) lag of the residuals is as follows:

$$
\boldsymbol{h}_{t}^{2}=\beta_{\mathrm{O}}+\sum_{i=1}^{q} \beta_{1} \varepsilon_{t-1}^{2}
$$

The above equation is what (Engle, 1982) referred to as the linear ARCH (q) model because of the inclusion of the (q) lags of the $\left(\varepsilon_{t}^{2}\right)$ in the variance equation. This model suggests that volatility in the current period is related to volatility in the past periods,

For example in the case of $\operatorname{AR}(1)$ model, If $\beta_{1}$ is positive, it suggests that if volatility was high in the previous period, it will continue to be high in the current period, indicating volatility clustering .If $\beta_{1}$ is zero, then there is no volatility clustering. 
To determine the value of $\mathrm{q}$ or the $\mathrm{ARCH}$ model order, we use the model selection criterion such as AIC (Akaike Information Criterion) and SBIC (Schwartz Bayesian Information Criterion). The decision rule is to select the model with the minimum value of information criterion. This condition is necessary but not enough because the estimate meets the general requirements of an ARCH model. The model to be adequate should have coefficient that all are significant. If this requirement meets then the specified model is adequate and fit the data well.

\subsection{GARCH Model}

The problem with applying the original ARCH model is the non-negativity constraint on the coefficient parameters of ( $\left.\beta i^{\prime} s\right)$ to ensure the positivity of the conditional variance. However, when a model requires many lags to model the process correctly the non-negativity may be violated.

To avoid the long lag structure of the ARCH (q) developed by , (Engle, 1982), (Bollerslev, 1986), generalized the ARCH model, the so-called (GARCH), by including the lagged values of the conditional variance. Thus, $\operatorname{GARCH}(\mathrm{p}, \mathrm{q})$ specifies the conditional variance to be a linear combination of $(\mathrm{q})$ lags of the squared residuals $\varepsilon_{t}^{2}$ from the conditional return equation and (p) lags from the conditional variance $\sigma_{t-j}^{2}$. Then, the $\operatorname{GARCH}(\mathrm{p}, \mathrm{q})$ specification can be written as follows:

$$
h_{t}^{2}=\beta_{0}+\sum_{i=1}^{q} \beta_{1} \varepsilon_{t-i}^{2}+\sum_{j=1}^{p} \beta_{2} h_{t-j}^{2} \quad \forall \mathrm{j}=1, \ldots \ldots \mathrm{p} \text { and } \mathrm{i}=1, \ldots \ldots . \mathrm{q}
$$

Where $\beta_{1}, \beta_{2}>0$ and $\left(\beta_{1}+\beta_{2}\right)<1$ is to avoid the possibility of negative conditional variance. The above equation states that the current value of the conditional variance is a function of a constant and values of the squared residual from the conditional return equation plus values of the previous conditional variance.

To show the significance of the explanation of conditional variance of one lag of both $\varepsilon_{t}^{2}$ and $h_{t}^{2}$, e.g. $\varepsilon_{t-1}$ and $h_{t-1}^{2}$, the GARCH process should be employed by estimating the conditional return to drive $\varepsilon_{t}^{2}$, and then the estimation of the conditional variance by using equation below

$$
\boldsymbol{h}_{t}^{2}=\beta_{\mathrm{O}}+\beta_{1} \varepsilon_{t-1}^{2}+\alpha_{1} \boldsymbol{h}_{t-1}^{2}
$$

The adequacy of the GARCH model can be examined by standardized residuals, $\left(\frac{\varepsilon}{\sigma}\right)$, where $(\sigma)$ is the conditional standard deviation as calculated by the GARCH model, and $(\varepsilon)$ is the residuals of the conditional return equation.

$$
R_{t}=\alpha_{0}+\sum_{i=1}^{p} \alpha_{1} R_{t-1}+\varepsilon_{t}
$$

If the GARCH model is well specified, then the standardized residuals will be Independent and Identically Distributed (IID).To shows this, two-step test is needed. The first step is to 
calculate the Ljung-Box Q-Statistics (LB) on the squared observation of the raw data. This test can be used to test for remaining serial correlation in the mean equation and to check the specification of the mean equation. If the mean equation is correctly specified, all Q-statistics should not be significant.

The next step is to calculate the $\mathrm{Q}$-statistics of the squared standardized residuals. This test can be used to test for remaining $\mathrm{ARCH}$ in the variance equation and to check the specification of the variance equation. If the variance equation is correctly specified, all $Q$-statistics should not be significant. Put another way, if the GARCH is well specified, then the LB statistic of the standardized residuals will be less than the critical value of the Chi-square statistic $\chi_{m-p-q}^{2}$ (Alsalman, 2002).

The test for mean equation specification can be thought of as a test for autocorrelation in the standardized residuals. The test is one of a joint null hypothesis that there is no autocorrelation up to order $\mathrm{k}$ of the residuals.

If the value of the test statistic is greater than theoretical value from the Q-statistics, then the null hypothesis can be rejected. Alternatively, if p-value is smaller than the conventional significance level, the null hypothesis that there are no autocorrelation will be rejected. In other words, the series under investigation shows volatility clustering or volatility persistence. The same is true for variance equation. The only difference is that in this case the test will be done on squared standardized residuals.

In addition to Ljang-Box Q-statistics the ARCH-LM test also can be used to test the adequacy of ARCH model. The procedure is same as ARCH model. To model selection, model selection criteria such as SBC and AIC are used.

The high or low persistence in volatility is generally captured in the GARCH coefficient(s) of a stationary GARCH model. For a stationary GARCH model the volatility mean reverts to its long run level at rate given by the sum of $\mathrm{ARCH}$ and $\mathrm{GARCH}$ coefficients, which is generally close to one for a financial time series. The average number of time periods for the volatility to revert to its long run level is measured by the half life of the volatility shock and it is used to forecast the TEPIX series volatility on a moving average basis (Banerjee and Sarkar, 2006).

A covariance stationary time series $\left\{y_{t}\right\}$ has an infinite order moving avarage representation of the form:

$$
y_{t}=\mu+\sum_{i=0}^{\infty} \psi_{i} \varepsilon_{t-i}, \quad \psi_{0}=1, \sum_{i=0}^{\infty} \psi_{i}^{2}<\infty
$$

The plot of the $\psi_{i}$ against $\mathrm{i}$ is called the Impulse Response Function (IRF).The decay rate of IRF is sometimes reported as a half-life, denoted by $L_{\text {half }}$ which is the lag at which the IRF reaches $\frac{1}{2}$.

\section{3.Calculation of half-life of volatility shock for a stationary $\operatorname{GARCH}(1,1)$ process}

The mean reverting form of the basic GARCH(1 11$)$ model is: 


$$
\left(\varepsilon_{t}^{2}-\bar{\sigma}^{2}\right)=\left(\alpha_{1}+\beta_{1}\right)\left(\varepsilon_{t-1}^{2}-\bar{\sigma}^{2}\right)+u_{t}-\beta_{1} u_{t-1}
$$

Where $\bar{\sigma}^{2}=\alpha_{0} /\left(1-\alpha_{1}-\beta_{1}\right)$ is the unconditional long run level of volatility and $u_{t}=$ $\left(\varepsilon_{t}^{2}-\sigma_{t}^{2}\right)$. The mean reverting rate $\alpha_{1}+\beta_{1}$ implied by most fitted models is usually very close to 1 . The magnitude of $\alpha_{1}+\beta_{1}$ controls the speed of mean reversion. The half life of a volatility shock is given by the formula

$$
L_{\text {nalf }}=\ln \left(\frac{1}{2}\right) / \ln \left(\alpha_{1}+\beta_{1}\right)
$$

Measures the average time it takes for $\left|\varepsilon_{t}^{2}-\bar{\sigma}^{2}\right|$ to decrease by one half. The closer $\alpha_{1}+\beta_{1}$ is to one the longer is the half life of a volatility shock. If $\alpha_{1}+\beta_{1}>1$, the GARCH model is nonstationary and the volatility will eventually explode to infinity (Banerjee and Sarkar, 2006).

\section{REVIEW OF LITERATURE}

Stock prices volatility is an extremely important concept in finance for numerous reasons. The literature on stock price volatility agrees on one key phenomenon. There is evidence of sever movements in stock prices. In other words, dynamic nature of stock prices behavior is an accepted phenomenon and all participants in stock markets include regulators, professionals and academics have consensus about it. But, what causes stock prices volatility is a question that remains unsettled in finance field. Answer to this question, because of the great number of involved variables is not an easy task and up to now there is no consensus about it. However, researchers in quest to answer this question have investigated the stock prices volatility from different angles. In this regards, from late twentieth century and particularly after introducing ARCH model by (Engle, 1982), as said by (Bollerslev, 1990) and (Granger and Poon, 2000) several hundred researches that mainly accomplished in developed country and to some extent in developing countries have been done in this area using different methodologies(See (Engle et al., 1987), (Glosten et al., 1993), (Nelson, 1991), (Engle and Victor, 1993) (Engle \& Ng, 1993), (Goudarzi and Ramanarayanan, 2010), (Goudarzi, 2011), (Goudarzi, 2013)). However, sanctions and its impacts on countries economy have been studied by several researchers from different point of views. However, lack of research on the impacts of sanctions on stock market volatility is evident and the existing papers focused mainly on overall impacts of sanctions on sanctioned economies as follows:

(Andreasson, 2008) studied the effects of sanctions on Burma which is a totalitarian military junta. Due to this feature, towards a democratization process, it is under pressure through sanctions by Western countries. He contends that, considering all aspects, every sanction situation is unique and thus wider generalizations are difficult to determine. Finally, he concluded that in the case of Burma, the effects of sanctions have clearly not been the best way of pressuring the government into changing its behavior. 
(Kudo, 2005) studied the impacts of united state sanction on Myanmar. He showed that overall effects of the sanctions were not behavior modifications, and thus he emphasized that it must be stated frankly that there are no observed signs that the military intends to change its behaviors or attitudes on freedom and democracy.

(Noland, 2008) studied the impacts of sanctions on North Korea. He found that North Korea's nuclear test and the imposition of UN Security Council sanctions have had no perceptible effect on North Korea's trade with its two largest partners, China and South Korea. He concluded that, if sanctions are to deter behavior in the future, they will have to be much more enthusiastically implemented.

\section{METHODOLOGY}

The required data including 3261 daily closing observation for TEPIX price index covering the period 02/01/2000 through 23/10/2013 were obtained from the Tehran Stock Exchange, and were based on daily closing prices. The TEPIX returns $\left(r_{t}\right)$ at time $\mathrm{t}$ are defined in the logarithm of TEPIX indices (p), that is, $r_{t}=\log \left(p_{t} / p_{(t-1)}\right)$.Visual inspection of the plot of daily returns series of TEPIX proved very useful. It can be seen that from figure 1 that return fluctuates around mean value that is close to zero. Volatility is high for certain time periods and low for other periods. The movements are in the positive and negative territory and larger fluctuations tend to cluster together separated by periods of relative calm. The volatility was highest in 2004 and 2008. Thus figure 1 shows volatility clustering where large returns tend to be followed by small returns leading to continuous periods of volatility and stability .Volatility clustering implies a strong autocorrelation in squared return.

The number of observation is 3261 .The mean daily return is 0.000480 .The volatility (measured as a standard deviation) is 0.002651 . There is indication of positive skewness (Skw= 0.441458) which indicates that the upper tail of the distribution is ticker than the lower tail, that is ,the index increases occur more often than its declines. The kurtosis coefficient is positive, having high value for the return series (Kurt $=12.72898)$ that is the pointer of leptokurtosis or fat taildness in the underlying distribution. In fact, under the null hypothesis of normality the Jarque-Bera statistic asymptotically follows a Qi-squire distribution with 2 degree of freedom. The computed value of 12962.94 with P-value of zero rejects the normality assumption due to the high kurtosis indicating fat tail .Q-Q plot in figure 2 also confirm the non-normality of the returns series.

As table.1 shows ARCH-LM test is statistically significant which indicates the presence of ARCH effect in the residuals of mean equation of TEPIX. The ADF test statistics rejects the hypothesis of unit root in the returns series at $1 \%$ level of significance.

A formal application of ADF test on log returns rejects the null hypothesis of a unit root in the return series. There is rejection at 0.01 level of significance because absolute value of ADF 
statistics -12.09649 exceeds McKinnon critical value -3.4321174 . These properties of the TEPIX returns series are consistent with other financial times series.

The ARCH and GARCH models are estimated for TEPIX returns series using the robust method of Bollerslev -Wooldridge's quasi-maximum likelihood estimator (QMLE) assuming the Gaussian standard normal distribution. Next, we use information criteria such as AIC, SBIC values, and a set of model diagnostic tests (ARCH-LM test and Q-Statistics) to choose the volatility models which represent the conditional variance of the TEPIX returns series appropriately.

\section{FINDINGS}

To detect the presence of $\mathrm{ARCH}$ effect in the mean equation of TEPIX the study used the ARCH-LM (Lagrange multiplier) test. We tested for ARCH-effect for higher order and found that coefficient of $\varepsilon_{t-3}^{2}, \varepsilon_{t-5}^{2}, \varepsilon_{t-6}^{2}$ and $\varepsilon_{t-8}^{2}$ found to be statistically insignificant .

ARCH-LM test is statistically significant which indicates the presence of ARCH effect in the residuals of mean equation of TEPIX [table1]. To determine which ARCH model is adequate for describing the conditional heteroscedasticity of the data at $5 \%$ significance level the study applied sample ACF and PACF of the squared residuals which showed the existence of ARCH effects. The sample PACF indicated that an ARCH (5) model might be appropriate. Consequently, the study specified the ARCH (5) model .The results for the ARCH (5) for daily log returns of TEPIX showed the estimates of $\alpha_{1}, \alpha_{2}, \alpha_{3}, \alpha_{4}$ and $\alpha_{5}$ were not all statistically significant at the $5 \%$ level of significance and the model has to be changed. Therefore, the study tests other ARCH order for the data set of TEPIX. Using the AIC, SBIC and Loglikelihood model selection criteria the study finally select the $\mathrm{ARCH}(3)$ model . The results for the ARCH (3) for daily log returns of TEPIX are reported in table 2 . As table 2 shows the estimates of $\alpha_{1}, \alpha_{2}$ and, $\alpha_{3}$ are all statistically significant at the $5 \%$ level of significance.

To test the adequacy of the model we applied the ARCH-LM test up to 10 lag. The result has reported in the table 3.As table 3 indicates, both test statistics are statistically insignificant. It means no ARCH effects left in the model. Thus, the study found that $\mathrm{ARCH}$ (3) can be possible representative of the conditional volatility process for daily returns series of TEPIX.

Although the ARCH model is simple, it often requires many parameters to adequately describe the volatility process of an asset returns. (Bollerslev, 1986), proposes a useful extension known as the generalized ARCH $(\mathrm{GARCH})$ model. The modeling process of $\mathrm{ARCH}$ models can also be used to build a GARCH model. However, specifying the order of GARCH model is difficult. For this reason only lower order of GARCH, models are used in most application. The study fits the GARCH models with different orders (up to 5) to the daily returns. To select the order of GARCH model, the study used SBC criteria. The model with lower value of SBC fits the data best. The results are presented in table 4 . As table 4 shows, The SBIC value is lowest for $\mathrm{p}=3$ and $\mathrm{q}=5$. However, close observation of the model showed negative and insignificant coefficients and 
$\mathrm{p}$ value, respectively. This was the case about other model except $\operatorname{GARCH}(1,1)$. Therefore, the study selects the GARCH $(1,1)$ for the data set of TEPIX. This means $\operatorname{GARCH}(1,1)$ can be possible representative of the conditional volatility process for daily returns series of TEPIX.Table5 reports the statistics regarding $\operatorname{GARCH}(1,1)$. To test the adequacy of GARCH $(1,1)$ model ARCH-LM test up to 10 lag was applied. The results of ARCH - LM test are reported in table 6. As results show the F-statistic and Obs*R-squared statistic both are insignificance and indicating no ARCH effects left in the series. Thus the study employed $\mathrm{GARCH}(1,1)$ to model volatility.

As above model indicates the value of $\alpha$ is 0.287841 and the value of $\beta$ is 0.635568 . The sum of parameters is 0.93 . The stationary condition $(\alpha+\beta)<1$ is satisfied. The mean reverting rate $(\alpha+\beta)=0.93$, implied by our fitted model is close to one. Therefore, the fitted GARCH model implies that conditional volatility is very persistent. A large value of GARCH lag coefficient $\beta$ (0.635568) indicates that shocks to conditional variance takes a long time to die out, so the volatility is persistent. Low value of error coefficient $\alpha$ i.e. (0.287841) suggests that large market surprises induce relatively small revision in future volatility. $(\alpha+\beta)=0.93$ is close to unity and implies that a shock at time t persists for many future periods. A high value of this kind implies a "long memory" in the stock market. Any shock will lead to a permanent change in all the future values of $h_{t}$, hence shocks to conditional variance are persistent.

To test the null of non stationary series or no mean reversion in the TEPIX returns two tests were applied. First the study used the unit root test. As it stated in the beginning of the chapter, the results of the ADF test showed that the series is stationary. In other words there was no evidence in favor of unit root in the data and we concluded that the data series is stationary. When the data series is stationary, it is mean reverting and volatility finally reverts to its long run average. Another way of testing mean reversion is using GARCH model. For a stationary GARCH model the volatility mean reverts to its long run level, at rate given by the sum of $\mathrm{ARCH}$ and GARCH coefficients, which is generally close to one for a financial time series. The average number of time periods for the volatility to revert to its long run level is measured by the half life of the volatility shock and it is used to forecast the TEPIX series volatility. Here the sum of ARCH and GARCH term is nearly 0.93 which is close to 1 . The mean reverting rate i.e. $\alpha_{1}+$ $\beta_{1}$ implied by our fitted model is very close to 1 . The magnitude of $\alpha_{1}+\beta_{1}$ controls the speed of mean reversion. The half life of a volatility shock Measures the average time it takes for $\left|\varepsilon_{t}^{2}-\bar{\sigma}^{2}\right|$ to decrease by one half the closer $\alpha_{1}+\beta_{1}$ is to one the longer is the half life of a volatility shock. If $\left(\alpha_{1}+\beta_{1}\right)>1$, the GARCH model is nonstationary and the volatility will eventually explode to infinity.

In our case it is almost 9.Therefore, the null hypothesis of unit root or no mean reversion is rejected and the study accepts the alternative hypothesis of stationary or mean reverting in the underlying series. 


\section{CONCLUSION}

As said in an introduction, sanctions have been applied to Iran since 1979 but became serious from 2010. Since then, U.S.A has instituted four major acts sanctioning Iran, impacting hundreds of companies, people, and assets. The U.S.A steadily applied broader unilateral sanctions and pushed its allies particularly EU to impose more sanctions against Iran. In the alliance, the EU has joined U.S.A in pressuring Iran by passing six major Council Decisions in the past three years (Cordesman, 2013). These harsh sanctions, impacted both Iran's economy and oil industry.

However, Iran's economy has hardly collapsed despite inflation, unemployment, and an uncertain exchange rate. Findings of this study support such a claim in three different ways. First, speed of mean reversion was approximately 9 days indicating that there is no sign of long shock that makes the stock market volatile. Second, close inspection of volatility shows highest volatility for period of 2006-2007 i.e. the starting point of harsh sanctions by the UN Security Council. Interestingly, after that i.e. during $2007-2013$, there was not any irregular volatility even after 2011-2012 new sanctions by U.S. and EU. Third, positive skewness as another measure also shows that the index increases has occurred more often than its declines.

These behaviors can be attributed to adaptation against sanctions and execution of internal confrontation against them. It is well documented that economic sanctions on their own have their greatest impact in the short term, as their effects tend to be mitigated in the longer term by structural economic and political adjustments (Pesaran, 2013). The Iranian targeted subsidy plan and resistance economy are among the most important strategies that Iranian authorities followed to deflect and deplete the sanctions consequences. Hence, based on the above mentioned argument, this study concludes that Iran's stock market has not affected by sanctions.

Funding: This study received no specific financial support.

Competing Interests: The author declares that there are no conflicts of interests regarding the publication of this paper.

\section{REFERENCES}

Alsalman, A., 2002. Empirical issues of financial market volatility in Kuwait stock exchange. Thesis . U.S.A: Howard University.

Andreasson, G., 2008. Evaluating the effects of economic sanctions against Burma. Lunds University.

Banerjee, A. and S. Sarkar, 2006. Modelling daily volatility of the Indian stock market using intra-day data. Working paper . IIM Calcutta.

Bollerslev, T., 1986. Generalized autoregressive conditional heteroskedasticity. Journal of Econometrics, 31(3): 307-327.

Bollerslev, T., 1990. Modelling the coherence in short-run nominal exchange rates: A multivariate generalized ARCH model. The Review of Economics and Statistics, 72(3): 498-505.

Brooks, C., 2002. Introductory econometrics for finance. Cambrige University Press.

Cordesman, A., 2013. U.S. and Iranian strategic competition. Center for Strategic \& International Studies. 
Engle, R., 1982. Autoregressive conditional heteroscedasticity with estimate of the variance of United Kingdom Inflation. Econometrica, 50(4): 987-1007.

Engle, R., D. Lilen and R. Robinz, 1987. Estimating time varying risk Permia in term structure: The ARCHM model. Econometrica, 55(2): 391-407.

Engle, R. and N. Victor, 1993. Measuring and testing the impact of news on volatility. Journal of Finance, 48(5): 1749-1778.

Glosten, Jagannathan and Runkle, 1993. On the relation between the expected value and the volatility of the nominal excess return on stocks. The Journal of Finance, 48(5): 1779-1801.

Goudarzi, H., 2011. Modelling asymmetric volatility in the Indian stock market. International Journal of Business and Management, 6(3): 221-231.

Goudarzi, H., 2013. Volatility mean reversion and stock market efficiency. Asian Economic and Financial Review, 3(12): 1681-1692.

Goudarzi, H. and C. Ramanarayanan, 2010. Modelling and estimation of volatility in the Indian stock market. Journal of Business and Management, 5(2): 85-98.

Government of Australia, 2013. Iran sanctions. Retrieved from department of foreign affairs and trade. Available from http://www.dfat.gov.au/un/unsc_sanctions/iran.html.

Granger, C. and H. Poon, 2000. Forecasting volatility in financial markets. Journal of Economic Litrature, $41(2): 478-539$.

Gujarati, D., 2007. Basic econometrics. New York: McGrawhill Publishing Company.

Hufbauer, G.C., 2007. Economic sanctions reconsidered. Washington: Peterson Institute.

Katzman, K., 2013. Iran sanctions. Congressional Research Services.

Kudo, 2005. The impacts of United State sanctions on the Myanmar Germant industry. Discussion paper No.42. Institute of Developing Economies.

Matthew, S., 2013. What is the effect of U.S.-Led sanctions on a target nation's foreign currency exchange rate? Washington.

Nelson, D., 1991. Conditional heterosjedasticity in asset returns: A new approach. Econometrica, 59(2): 347370.

Noland, M., 2008. The (Non) impact of UN sanctions on North korea. Working paper series No.WPo8-12 . Peterson Institute for International Economics.

Pesaran, M.H., 2013. Iran sanctions: Now is the time to negotiate. Tehran: Thegaurdian.

Tehran Stock Exchange, 2013. Tehran stock exchange. Available from http://www.tse.ir.

Torbat, A., 2012. Eu embargoes iran over the nuke issue. Information clearing house.

Zivot, E. and Wang, 2006. Modelling financial time series with S-plus. Springer.

Table- 1. ARCH-LM test of TEPIX log returns series up to 10 lags

\begin{tabular}{llll}
\hline \multicolumn{4}{l}{ ARCH-LM TEST } \\
\hline F-statistics & 53.79811 & Probability & 0.0 \\
\hline Obs*R-Squared & 429.9781 & Probability & 0.0 \\
\hline
\end{tabular}


Table- 2. ARCH (3) model parameters

\begin{tabular}{ccccc}
\hline \multicolumn{5}{c}{ ARCH (3) Model Parameters } \\
\hline \multicolumn{5}{c}{ Mean Equation } \\
\hline $\mathrm{C}$ & Coefficient & Std. Error & z-Statistic & Prob. \\
\hline $\mathrm{AR}(1)$ & 0.000266 & $6.27 \mathrm{E}-05$ & 4.238525 & 0.0000 \\
\hline $\mathrm{C}$ & 0.477988 & 0.023017 & 20.76663 & 0.0000 \\
\hline $\mathrm{ARCH}(1)$ & $1.86 \mathrm{E}-06$ & Variance Equation & & 0.0000 \\
\hline $\mathrm{ARCH}(2)$ & 0.362618 & $2.09 \mathrm{E}-07$ & 8.929930 & 0.0000 \\
\hline $\mathrm{ARCH}(3)$ & 0.146995 & 0.061475 & 5.900244 & 0.0000 \\
\hline
\end{tabular}

Table-3. ARCH-LM Test for ARCH (3) Model Up to $10 \mathrm{Lag}$

\begin{tabular}{|c|c|c|c|}
\hline \multicolumn{4}{|c|}{$\operatorname{ARCH}(3)$ Test } \\
\hline F-statistics & 0.310357 & Probability & 0.9788 \\
\hline Obs*R-Squared & 9.192570 & Probability & 0.9787 \\
\hline
\end{tabular}

Table- 4. SBIC for different Garch model

Comparisons of the SBC for the GARCH(p,q) model with different combinations of $p$ and $q$ for TEPIX

\begin{tabular}{cccccc}
\hline $\mathrm{p}$ & 1 & 2 & 3 & 4 & 5 \\
\hline $\mathrm{q}$ & & & & & -9.595538 \\
\hline 1 & -9.550193 & -9.576268 & -9.580131 & -9.596389 & -9.601604 \\
\hline 2 & -9.570389 & -9.573950 & -9.577222 & -9.595243 & -9.598700 \\
\hline 3 & -9.571300 & -9.588625 & -9.588867 & -9.593735 & -9.597000 \\
\hline 4 & -9.569197 & -9.593233 & -9.596857 & -9.592095 & -9.591580 \\
\hline 5 & -9.591067 & -9.600757 & $\mathbf{- 9 . 6 0 1 6 9 2}$ & -9.599222 & \\
\hline
\end{tabular}

Table- 5. GARCH $(1,1)$ parameters

\begin{tabular}{ccccc}
\hline \multicolumn{5}{c}{ GARCH(1, 1) Parameters } \\
\hline \multicolumn{5}{c}{ Mean equation } \\
\hline $\mathrm{C}$ & Coefficient & Std. Error & z-Statistic & Prob. \\
\hline $\mathrm{AR}(1)$ & 0.000258 & $6019 \mathrm{E}-05$ & 4.166790 & 0.0000 \\
\hline $\mathrm{C}$ & 0.497680 & 0.020864 & 23.85367 & 0.0000 \\
\hline ARCH(1) & $5.84 \mathrm{E}-07$ & $1.69 \mathrm{E}-07$ & 3.453410 & 0.0006 \\
\hline GARCH(1) & 0.287841 & 0.053749 & 5.355333 & 0.0000 \\
\hline
\end{tabular}


Table- 6.ARCH-LM test for GARCH(1,1) model up to 10 lag

\begin{tabular}{cccc}
\hline \multicolumn{4}{c}{ ARCH(10) test } \\
\hline F-statistics & 1.211783 & Probability & 0.2778 \\
\hline Obs*R-Squared & 6.357489 & Probability & 0.2775 \\
\hline
\end{tabular}

Figure- 1. The Residuals of TEPIX Returns

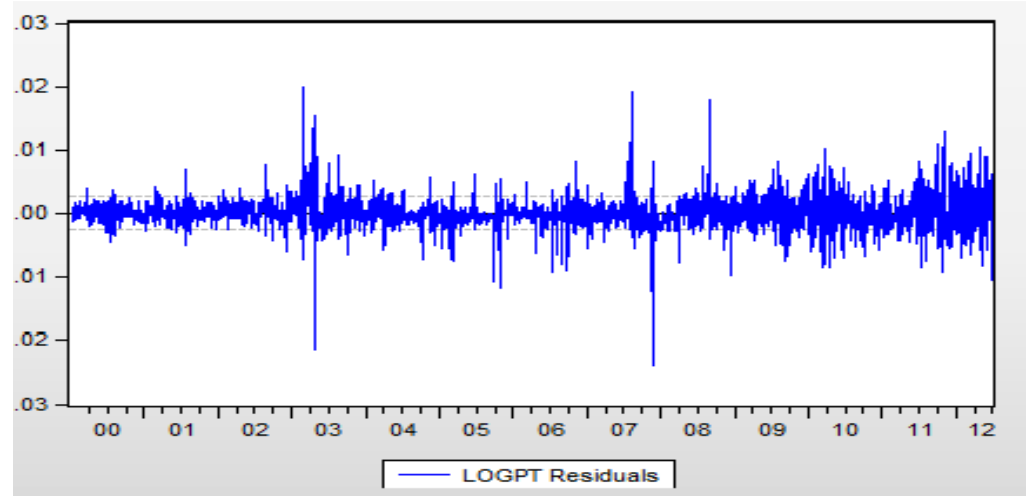

Figure- 2. Q-Q Plot of TEPIX Daily Returns Series

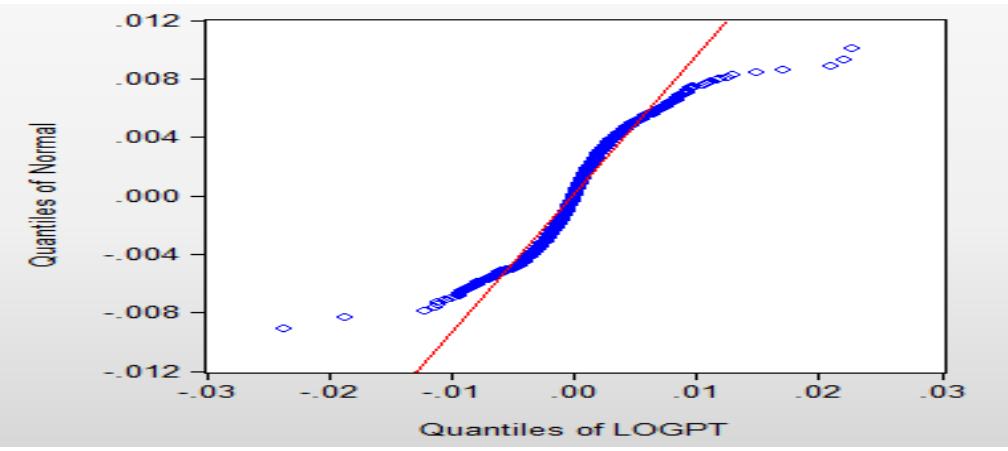

